\title{
New Insights into cytotoxic metabolites produced by Streptomyces griseus isolate KJ623766: Large scale production, structure elucidation and biological activities
}

\author{
Ahmed S. Abu Zaid \\ Ain Shams University Faculty of Pharmacy \\ Ahmed E. Aleissawy \\ Ain Shams University Faculty of Pharmacy \\ Khaled Aboshanab ( $\square$ aboshanab2012@pharma.asu.edu.eg ) \\ Ain Shams University Faculty of Pharmacy https://orcid.org/0000-0002-7608-850X \\ Mahmoud A. Yassien \\ Ain Shams University Faculty of Pharmacy \\ Nadia A. Hassouna \\ Ain Shams University Faculty of Pharmacy
}

Research article

Keywords: cytotoxic metabolites; natural products; genistein; S. griseus; $\beta$-rhodomycinone; $ү$ - rhodomycinone.

Posted Date: October 14th, 2019

DOI: https://doi.org/10.21203/rs.2.13866/v2

License: (c) (i) This work is licensed under a Creative Commons Attribution 4.0 International License. Read Full License 


\section{Abstract}

Natural products particularly microbial metabolites have been the mainstay of cancer chemotherapy and are likely to provide many of the lead structures and derivatives with new biological activities. In this research, the production of some potential cytotoxic metabolites from Streptomyces (S.) griseus isolate KJ623766 was carried out in $14 \mathrm{~L}$ laboratory fermenter under specified optimum conditions $\left(28^{\circ} \mathrm{C}\right.$ temperature, $200 \mathrm{RPM}$ rotation speed, uncontrolled $\mathrm{PH}, 3$ vvm aeration and 2 bar airflow pressure). Using 3-(4,5-dimethylthazol-2-yl)-2,5-diphenyl tetrazolium-bromide (MTT) assay, the cytotoxic activity of the ethyl acetate $(1: 1, \mathrm{v} / \mathrm{v})$ extract of cell free culture supernatant (CFCS) against Caco2 and Hela cancer cell lines was determined with CD 50 of $14 \mu \mathrm{g} / \mathrm{ml}$ and $20 \mu \mathrm{g} / \mathrm{ml}$, respectively. Bioassay guided fractionation of the ethyl acetate extract using different chromatographic techniques had led to the purification of the cytotoxic metabolites coded W1, R1 and R2 with reproducible amounts of 20, 5, and 1.5 mg/l, respectively. The structures of respective metabolites were determined using various spectroscopic analysis and identified as genistein, $\beta$-rhodomycinone and $\gamma$-rhodomycinone, respectively. Accordingly, S. griseus isolate KJ623766 can be used as a potential industrial strain for the large scale production of the isoflavonoid genistein, as well as for the production of $\beta$-and $\gamma$-rhodomycinone to be used for the construction of new derivatives with more potent cytotoxic activities of the anthracycline family. This is the first report about the production of the isoflavonoid genistein by S. griseus KJ623766.

\section{Introduction}

Cancer diseases are a major health problem in both developed and developing countries. Therefore, combating against cancer requires integration between primary, secondary, and tertiary medical care in any nation [1]. Liver cancer is most prevalent cancer in the some countries such as Egypt and Saudi Arabia particularly in men while colorectal cancer is the second highest cause of malignancy and death in both sex in the USA[2,3]. On the other hand, breast cancer is the most frequently diagnosed cancer and the leading causing of cancer death in females, worldwide [4]. Moreover, cervical cancer is the third leading cause of cancer death among females in the less developed countries [5,6].

Natural products particularly microbial metabolites have been the mainstay of cancer chemotherapy and are likely to provide many of the lead structures, that can be used as models for the discovering of new derivatives with improved biological activities [7]. These chemotherapeutic agents isolated from plant, marine and bacterial sources are commonly used in chemotherapy as well as to treat lupus and juvenile rheumatoid arthritis[8]. Various members of Streptomyces have made imperative contributions to human with their capabilities to produce various important active metabolites including antimicrobial, antioxidant, anticancer agents [8-10]. Many drugs such as bleomycins, dactinomycin, mitomycin C, daunomycin and doxorubicin originating from Streptomycetes are currently used in the treatment of cancer ande most of them were introduced into clinic before discovering their modes of actions [7]. Therefore, this study aimed at production, purification, structural elucidation and determining the biological activities of certain metabolites produced by S. griseus KJ623766, a recovered soil isolate previously screened in our lab to have a promising cytotoxic activities against various cancer cell lines[11]

\section{Materials And Methods}

\section{Microorganisms}


Locally isolated Streptomyces strain from Egyptian soil sample, S. griseus KJ623766, identified using 16S ribosomal RNA gene sequences (NCBI GenBank access code, KJ623766) [11]. The isolate was preserved onto starch nitrate agar slants slant (soluble starch $10 \mathrm{gm}, \mathrm{KNO}_{3} 2 \mathrm{gm}, \mathrm{K}_{2} \mathrm{HPO}_{4} 1 \mathrm{gm}, \mathrm{NaCl} 0.5 \mathrm{gm}, \mathrm{MgSO}_{4} .7 \mathrm{H}_{2} \mathrm{O} 0.5 \mathrm{gm}$, $\mathrm{CaCO}_{3} 3 \mathrm{gm}$, agar $20 \mathrm{gm}, \mathrm{FeSO}_{4} .7 \mathrm{H}_{2} \mathrm{O} 0.1 \mathrm{gm}, \mathrm{MnCl}_{2} 4 \mathrm{H}_{2} \mathrm{O} 0.1 \mathrm{gm}, \mathrm{ZnSO}_{4} 7 \mathrm{H}_{2} \mathrm{O} 0.1 \mathrm{gm}$ per 1 liter of distilled water) and sub cultured every month. While slant-medium (50:50) (tryptone $10 \mathrm{gm}$, yeast extract $5 \mathrm{gm}$, glycerine $500 \mathrm{ml}$ and distilled $\mathrm{H}_{2} \mathrm{O}$ to $1 \mathrm{~L}$ ) was used for long term preservation.

\section{Cell lines}

Three cell lines including, kidney epithelial cells derived from the African green monkey (Vero cell line, ATCC No.CCL-81), colorectal adenocarcinoma derived from human colon (Caco-2 cell line) and epitheliod carcinoma derived from human cervix (HeLa cell line) were obtained from VACSERA, Egypt. The Caco-2 and HeLa cell lines were used to study the cytotoxic activities of the crude extract and isolated metabolites; stock culture of these cell lines was grown in T-75 tissue culture flasks containing $20 \mathrm{ml}$ of RPMl-1640 medium with 1\% antibiotic antimycotic solution and $10 \%$ fetal bovine serum. The medium was changed at $48 \mathrm{~h}$ intervals and cells dissociated with trypsin solution $(0.25 \%$ in phosphate buffer saline). Vero cell line is a continuous non-tumourigenic when a cell passage was not prolonged [12] and was used to analyze the cytotoxic activities of isolated metabolites. It was propagated in Eagle minimum essential medium (EMEM) with Hank's balanced salt solution (HBSS), supplemented with $10 \%$ Fetal bovine serum (FBS) and antibiotics (100 IU penicillin and $100 \mathrm{IU}$ streptomycin/ml) solution, and maintained in EMEM with Earl's balanced salt solution (EBSS) supplemented with 2\% FBS and antibiotics solution[12].

\section{Production of cytotoxic agent(s) by S. griseus KJ623766}

\section{Preparation of seed culture}

This was carried out according to Yin et al. [13] with some modifications as follows; surface inoculation of the tested isolate onto starch nitrate agar slant was carried out. After 7 days of incubation at $28^{\circ} \mathrm{C}$, the formed spores were scalped from the agar surface and suspended in $3 \mathrm{ml}$ distilled water. An aliquot (200 $\mu \mathrm{l})$ of the resulting spore bacterial suspension was used to inoculate $10 \mathrm{ml}$ of the soybean meal medium (soybean $15 \mathrm{gm}$, glucose $15 \mathrm{gm}$, $\mathrm{NaCl} 5 \mathrm{gm}, \mathrm{CaCO}_{3} 1 \mathrm{gm}$ per $1 \mathrm{~L}$ of distilled water in $100 \mathrm{ml}$ flask) and incubated at $28^{\circ} \mathrm{C}$ with shaking $200 \mathrm{RPM}$ for 72 hrs in C5KC shaking incubator (New Brunswick scientific, Edison, New jersey, USA). The culture obtained was used to inoculate the main culture.

\section{Fermentation in a laboratory fermenter}

This was done according to Radwan et al. [14] with some modifications, where the fermentation process was conducted in 14 L CelliGen 310 bioreactor (New Brunswick Scientific, Edison, NJ, USA), with its Reactor Process Control (RPC) software. Fermentation process was carried out using 5 liters working volume of soybean meal medium under a condition of $28^{\circ} \mathrm{C}$ incubation temperature; 200 RPM agitation speed, 3 vvm i.e 15 SLPM aeration rate and 2 bar airflow pressure. The dissolved oxygen concentration was adjusted to obtain $100 \%$ saturation at the beginning of the run and DO percentage was sensed by the DO probe and monitored during the fermentation process. $\mathrm{PH}$ was adjusted at $\mathrm{PH} 7$ at the beginning of the run, remains uncontrolled along the fermentation process (72 h). After inoculation with 3 days age culture of the test isolate $(5 \% \mathrm{v} / \mathrm{v})$ under aseptic conditions, the run started under the previously stated conditions. Fermentation process was left for $72 \mathrm{~h}$ during which foam was suppressed using silicon oil. The culture obtained was centrifuged at 6000 RPM for 10 min using EBA20 Centrifuge (Hettrich, Germany) and the cell free culture supernatant (CFCS) obtained was collected. 


\section{Extraction of cytotoxic metabolite(s)}

$1 \mathrm{~L}$ of CFCS was extracted with ethyl acetate at the level of 1:1 (v/v) in subsequent manner $[15,16]$ and the collected organic layers were evaporated using rotavapour (Heidolph instruments $\mathrm{GmbH}$ and Co. Schwabach, Germany) under vacuum at $45^{\circ} \mathrm{C}$. After complete evaporation, sample of the fraction residue was redissolved in $1.25 \%$ DMSO in tissue culture medium. The cytotoxic activity of the redissolved fraction was evaluated against Caco2 and Hela cancer cell lines using MTT assay. According to the screening program of American National Cancer Institute $(\mathrm{NCl})$, a crude extract is generally considered to have in vitro cytotoxic activity if the $\mathrm{CD}_{50}$ value is $\leq$ $30 \mu \mathrm{g} / \mathrm{m}$

\section{Isolation of the cytotoxic metabolite(s)}

Medium pressure chromatographic separations were carried out with a PuriFlash 4100 system (Interchim; Montluçon, France) consisting of a mixing HPLC quaternary pump, a PDA-UV-Vis detector 190-840nm, a fraction collector, and a sample loading module. For system controlling and process monitoring, Interchim Software 5.0 was used. $360 \mathrm{mg}$ sample was dissolved in $50 \mathrm{~mL}$ of methanol then introduced into the column via dry load using $4 \mathrm{gm}$ silica. Elution started with hexane:ethyl acetate (100\%:0\%) followed by ethyl acetate:methanol (100\%:0\%) gradient to yield 117 fractions. Elution was monitored using TLC (normal phase silica gel precoated plates F254, Merck, Germany) with UV-detection and spraying with vanillin sulphuric acid spray reagent to yield 12 major fractions (SG1-SG12); these fractions were subjected to MTT assay to measure cytotoxic activity of each against Caco-2 and Hela cell lines. Final purification steps were performed using preparative HPLC (Knauer, Germany) on Kromasil ODS preparative column $(10 \mathrm{~mm} \times 250 \mathrm{~mm})$ at flow rates $4 \mathrm{ml} / \mathrm{min}$ and UV detection at 254, yielding metabolites W1, R1 and R2. MTT assay was carried out to measure cytotoxic activity of each against Vero, Caco-2 and Hela cell lines.

\section{Spectroscopic analysis of the recovered cytotoxic metabolites}

Structures of the isolated metabolites were determined based on LCESIMS analysis performed using waters ${ }^{\circledR x}$ xevotqd ${ }^{\circledR}$ (USA) and NMR spectroscopic analysis which recorded (Bruker AVANCE HD III 400 MHz spectrometer; Switzerland). Methanol-d4 or chloroform-d3 solvent (Sigma Aldrich, Germany) was used to dissolve the NMR samples and transferred to three mm NMR tubes thereafter (Bruker).

\section{Cytotoxicity assay using MTT method}

MTT assay was performed as described by Saliba et al. [17] with some modifications as follows; about $100 \mu$ l of the tested metabolite ( $1 \mathrm{mg}$ of the metabolite dissolved in 5\% DMSO and tissue culture medium) was added to the well that contain $100 \mu \mathrm{l}$ of tissue culture medium, followed by two fold serial dilution. A total of 12 dilutions were used for each metabolite to calculate $C D_{50}$ for each. Control wells contained two aliquots of $100 \mu$ l of ethyl acetate extract of soybean meal medium (1 mg dissolved in 5\% DMSO and tissue culture medium) and $100 \mu$ l of tissue culture medium, followed by two fold serial dilutions.

After $24 \mathrm{hrs}$ incubation period at $37^{\circ} \mathrm{C}$ in $\mathrm{CO}_{2}$ incubator, wells were washed with PBS, followed by incubation with $100 \mu \mathrm{l} \mathrm{MTT}$ solution $(1 \mathrm{mg} / \mathrm{ml})$ per each well for $1 \mathrm{hr}$ at $37^{\circ} \mathrm{C}$. Supernatants were obtained by decantation and the cells were mixed with $100 \mu \mathrm{l}$ DMSO per each well to dissolve formazan particles. Elutes of the 12 wells of each tested metabolite were obtained and measured spectroscopically at $540 \mathrm{~nm}$ using differential wave length of 630 $\mathrm{nm}$ in Platos R496 Microplate reader AMD diagnostics, Graz, Austria. Control wells were in the same way handled and the \% cytotoxicity determined as follows [16]. 
Cytotoxicity $\%=1-\left\{A_{540}\right.$ of test culture/ $A_{540}$ of control culture $\} \times 100$. [16].

\section{Results}

\section{Cytotxic activities of the CFCS ethyl acetate extract}

The results showed that the CFCS ethyl acetate extract has potential cytotoxic activities against both cell lines with higher activity against $\mathrm{Caco} 2\left(\mathrm{CD}_{50} 14 \mu \mathrm{g} / \mathrm{ml}\right)$ than Hela cell line $\left(\mathrm{CD}_{50} 20 \mu \mathrm{g} / \mathrm{ml}\right)$, which indicates the presence of metabolites with higher selectivity to human colorectal adenocarcinoma.

\section{Isolation and purification of cytotoxic metabolite(s)}

As determined by TLC with UV-detection and spraying with vanillin sulphuric acid spray reagent, a total of 12 major fractions (SG1-SG12) were obtained. All the fractions were subjected to MTT assay to measure the cytotoxic activity of each. The fraction SG-3 (70\% Hexane) revealed a promising cytotoxic activity against Caco-2 and Hela cell lines $\left(C_{50}\right.$ equals to $9.4 \mu \mathrm{g} / \mathrm{ml}$ and $12.2 \mu \mathrm{g} / \mathrm{ml}$, respectively). Results of TLC indicate the presence of two major metabolites and one minor metabolite. So further purification of the active fraction SG-3 was carried out using semi-preparative HPLC, by which three pure metabolites namely, W1, R1 and R2 were recovered (Fig. 1).

\section{Cytotoxic activities of the recovered metabolites (W1, R1 and R2)}

The cytotoxic activities against of the three metabolites, W1, R1 and R2 against Caco2 and Hela cell lines were measured and lower cytotoxic activities were observed against Vero cell line (Table 1). Being cancer cell lines, Caco2 and Hela cell lines have lost their normal regulation of growth or cell death and were more sensitive to the effect of cytotoxic agents than Vero cell line.

Table 1 Cytotoxic activities of ethyl acetate extract and isolated metabolites against different cell lines.

\begin{tabular}{cccc}
\hline Tested metabolite & \multicolumn{3}{c}{ Cytotoxic activity $\left(\mathrm{CD}_{50}\right)$ against different cell lines $(\mu \mathrm{g} / \mathrm{ml})$} \\
\cline { 2 - 4 } & Caco2 & Hela & Vero \\
Ethyl acetate extract & 14 & 20 & \\
Fraction SG-3 & 9.4 & 12.2 & 43 \\
W1 & 4.05 & 5.4 & 64.8 \\
R1 & 6.3 & 9.45 & \\
& & & 67.3 \\
\hline
\end{tabular}

\section{Identification and cytotoxic activities of the recovered metabolites}

\section{Metabolite W1}

Metabolite W1 $(20 \mathrm{mg}$ ) was isolated as white amorphous powder. ESI-MS revealed pseudomolecular ion peak at $\mathrm{m} / \mathrm{z} 268.99(\mathrm{M}-\mathrm{H})^{-}$(Fig. 2) equivalent to the molecular formula $\mathrm{C}_{15} \mathrm{H}_{10} \mathrm{O}_{5}$. Interpretation of the ${ }^{1} \mathrm{H}$ NMR spectrum of W1 (Fig. 3) revealed typical pattern of isoflavonoid aglycone derivatives with distinct singlet signal at $\delta \mathrm{H} 8.07$ (s, $1 \mathrm{H})$ characteristic for $\mathrm{H}-2$ of the isoflavonoids, in addition to the presence of the para-disubustituted aromatic 
system with two sets of ortho coupled protons at $\delta \mathrm{H} 7.39(\mathrm{~d}, 8.1,2 \mathrm{H})$ and $6.86(\mathrm{~d}, 8.1,2 \mathrm{H})$ matching to $\mathrm{H}^{\prime} 2^{\prime}, 6^{\prime}$ and $\mathrm{H}-3^{\prime}, 5^{\prime}$, respectively. Finally the presence of two Meta coupled protons at $\delta \mathrm{H} 6.35(\mathrm{~d}, 2.1,1 \mathrm{H})$ corresponding to $\mathrm{H}-6$ and $\delta \mathrm{H} 6.23(\mathrm{~d}, 2.1,1 \mathrm{H})$ corresponding to $\mathrm{H}-8$. The APT spectrum of W1 revealed the presence of thirteen carbon signals classified as five methine signals and eight quaternary signals. The 1H and APT spectra of W1 (Table 2) were identical to those of the isoflavonoid aglycone genistein, thus metabolite W1 was identified as genistein (Supplementary Fig. 1S)

Table 2 NMR data of metabolite W1, Chemical shifts are expressed in $\delta \mathrm{H}$ values (ppm) from internal TMS. Coupling constants in parentheses ar€ in $\mathrm{Hz}$.

\begin{tabular}{ccc}
\hline Position & $\delta_{\mathrm{H}}(\mathrm{DMSO}-d 6,400 \mathrm{MHz}, \mathrm{Jin} \mathrm{Hz})$ & $\delta_{\mathrm{C}}(\mathrm{DMSO}-d 6,100 \mathrm{MHz})$ \\
\hline 2 & $8.29(s, 1 \mathrm{H})$ & $154.3(\mathrm{CH})$ \\
3 & & $121.7(\mathrm{C})$ \\
4 & & $180.1(\mathrm{C})$ \\
$4 \mathrm{a}$ & & $104.7(\mathrm{C})$ \\
5 & $12.95(s, 5-\mathrm{OH})$ & $162.4(\mathrm{C})$ \\
6 & $6.21(d, 2.1,1 \mathrm{H})$ & $99.5(\mathrm{CH})$ \\
7 & & $165.1(\mathrm{C})$ \\
8 & $6.36(d, 2.1,1 \mathrm{H})$ & $94.17(\mathrm{CH})$ \\
$8 \mathrm{a}$ & & $158.0(\mathrm{C})$ \\
$1^{\prime}$ & & $122.7(\mathrm{C})$ \\
$2^{\prime}, 6^{\prime}$ & $7.37(d, 8.6,2 \mathrm{H})$ & $130.6(\mathrm{CH})$ \\
$3^{\prime}, 5^{\prime}$ & $6.82(d, 8.6,2 \mathrm{H})$ & $115.5(\mathrm{CH})$ \\
$4^{\prime}$ & & $157.8(\mathrm{C})$ \\
\hline
\end{tabular}

\section{Metabolite R1}

Metabolite R1 (5mg) was isolated as reddish powder, ESI-MS revealed pseudomolecular ion peak at $m / z 385.05$ (M$\mathrm{H})^{-}$(Fig. 4) equivalent to molecular formula $\mathrm{C}_{20} \mathrm{H}_{18} \mathrm{O}_{8}$. The ${ }^{1} \mathrm{H}$ NMR of R1 (Fig. 5) revealed typical pattern of anthracycline derivatives, showing three chelating hydroxyl groups at $\delta \mathrm{H} 12.15,12.90,13.61$ corresponding to $4-\mathrm{OH}$, $6-\mathrm{OH}$ and $11-\mathrm{OH}$, respectively. The spectrum showed the presence of three adjacent aromatic protons at $\delta \mathrm{H} 7.93$ $(\mathrm{dd}, 7.4,1.2,1 \mathrm{H}), \delta \mathrm{H} 7.76(\mathrm{~m}, 1 \mathrm{H})$ and $\delta \mathrm{H} 7.37(\mathrm{dd}, 8.4,1.2,1 \mathrm{H})$, corresponding to $\mathrm{H}-1, \mathrm{H}-2$ and $\mathrm{H}-3$, respectively. The presence of two deshielded methine protons at $\delta \mathrm{H} 5.25(\mathrm{~m}, 1 \mathrm{H})$ and $\delta \mathrm{H} 4.91(\mathrm{brs}, 1 \mathrm{H})$ suggested the presence of two tertiary alcohol methine protons at $\mathrm{H}-7$ and $\mathrm{H}-10$ respectively.

This is confirmed by COSY correlations where $\mathrm{H}-7$ showed strong correlations with the methylene protons $\mathrm{H}-8 \mathrm{a}$ and $\mathrm{H}-8 \mathrm{~b}$ at $\delta \mathrm{H} 2.19(\mathrm{~m}, 1 \mathrm{H})$ and $\delta \mathrm{H} 2.22(\mathrm{~m}, 1 \mathrm{H})$. The comparison of ${ }^{1} \mathrm{H}$ NMR spectrum of R1 (Table 3 ) with that of known anthracyclins in the literature showed strong similarity to the known metabolite $\beta$-rhodomycinone (Supplementary Fig. 2S).

Table 3 NMR data of metabolites R1, R2 and $\gamma$ - rhodomycinone [18], Chemical shifts are expressed in $\delta H$ values (ppm) from internal TMS. Coupling constants in parentheses are given in $\mathrm{J}$ in $\mathrm{Hz}$. 


\begin{tabular}{|c|c|c|c|}
\hline osition & $\delta_{\mathrm{H}}\left(\mathrm{CDCl}_{3}, 400 \mathrm{MHz}, \mathrm{Jin} \mathrm{Hz}\right)$, Metabolite R1 & $\delta_{\mathrm{H}}\left(\mathrm{CDCl}_{3}, 400 \mathrm{MHz}\right.$, Jin Hz), Metabolite R2 & $\delta_{\mathrm{H}}\left(\mathrm{CDCl}_{3}\right) y$-rhodomycinone \\
\hline 1 & $7.93(d d, 7.4,1.2 .1 \mathrm{H})$ & $7.91(d d, 7.8 .1 .0,1 \mathrm{H})$ & $7.91(d d, 7.8 .1 .1,1 \mathrm{H})$ \\
\hline 2 & $7.76(t, 8.0,1 \mathrm{H})$ & $7.73(t, 8.0,1 \mathrm{H})$ & $7.75(t, 7.9,1 \mathrm{H})$ \\
\hline 3 & $7.37(d d, 8.4,1.2,1 \mathrm{H})$ & $7.35(d d, 8.2,1.0,1 \mathrm{H})$ & $7.41(d d, 7.8 .1 .1,1 \mathrm{H})$ \\
\hline 7 & $5.26(m, 1 \mathrm{H})$ & 7a: $2.98(m, 1 \mathrm{H}), 7 \mathrm{~b}: 2.90(m, 1 \mathrm{H})$ & $2.98-2.82(m, 2 \mathrm{H})$ \\
\hline $8 a$ & $2.19(m, 1 \mathrm{H})$ & $2.10(m, 1 \mathrm{H})$ & $2.29-2.14(m, 2 \mathrm{H})$ \\
\hline $8 b$ & $2.22(m, 1 \mathrm{H})$ & $2.35(m, 1 \mathrm{H})$ & \\
\hline 10 & $4.91(s, 1 \mathrm{H})$ & $4.82(s, 1 \mathrm{H})$ & $4.81(\mathrm{~s}, 1 \mathrm{H})$ \\
\hline $4-\mathrm{OH}$ & $12.15(s, 1 \mathrm{H})$ & $12.27(s, 1 \mathrm{H})$ & $12.20(s, 1 \mathrm{H})$ \\
\hline $6-\mathrm{OH}$ & $12.91(s, 1 \mathrm{H})$ & $12.77(s, 1 \mathrm{H})$ & $12.90(s, 1 \mathrm{H})$ \\
\hline |1-OH & $13.61(s, 1 \mathrm{H})$ & $13.87(s, 1 \mathrm{H})$ & $13.60(s, 1 \mathrm{H})$ \\
\hline 1 'a & $1.81(m, 1 \mathrm{H})$ & $1.95(m, 1 \mathrm{H})$ & $1.9-1.7(\mathrm{~m}, 2 \mathrm{H})$ \\
\hline 1 'b & $1.92(m, 1 \mathrm{H})$ & $2.00(m, 1 \mathrm{H})$ & \\
\hline $2^{\prime}$ & $1.15(t, 7.5,3 \mathrm{H})$ & $1.13(t, 7.5,3 \mathrm{H})$ & $1.03(t, 7.5,3 \mathrm{H})$ \\
\hline
\end{tabular}

$\beta$ - rhodomycinone showed potent cytotoxic activity against Caco2 and Hela cell lines, the $\mathrm{CD}_{50}$ were $6.3 \mu \mathrm{g} / \mathrm{ml}$ and $9.45 \mu \mathrm{g} / \mathrm{ml}$, respectively. While lower cytotoxic activity was showen against Vero cell line $\left(\mathrm{CD}_{50}=64.8 \mu \mathrm{g} / \mathrm{ml}\right)$.

\section{Metabolite R2}

The metabilite R2 (1.5 mg), red colored metabolite, showed identical ${ }^{1} \mathrm{HNMR}$ spectrum to R1 except in the replacement of $\mathrm{H}-7$ at $\delta \mathrm{H} 5.25(\mathrm{~m}, 1 \mathrm{H})$ in R1 with the methylene protons $\delta \mathrm{H} 2.98(\mathrm{~m}, 1 \mathrm{H})$ and $2.90(\mathrm{~m}, 1 \mathrm{H})$ corresponding to $\mathrm{H}-7 \mathrm{a}$ and $\mathrm{H}-7 \mathrm{~b}$ in R2 (Fig. 6). Comparison of ${ }^{1} \mathrm{HNMR}$ spectrum of R2 (Table 3) with that of known anthracyclins in the literature showed strong similarity to the known metabolite $\gamma$ - rhodomycinone (Supplementary Fig. 3S). This was confirmed by EZI-MS which revealed pseudomolecular ion peak at m/z $369.09(\mathrm{M}-\mathrm{H})^{-}$with the molecular formula $\mathrm{C}_{20} \mathrm{H}_{18} \mathrm{O}_{7}$ (Fig. 7).

The same as $\beta$-rhodomycinone, $\gamma$ - rhodomycinone showed potent cytotoxic activity against Caco2 and Hela cell lines, the $\mathrm{CD}_{50}$ were $7.11 \mu \mathrm{g} / \mathrm{ml}$ and $9.35 \mu \mathrm{g} / \mathrm{ml}$ respectively. While lower cytotoxic activity was shown against Vero 
cell line $\left(\mathrm{CD}_{50}=67.3 \mu \mathrm{g} / \mathrm{ml}\right)$.

\section{Discussion}

In this study, we aimed at identifying the major active metabolites produced by S. griseus KJ623766, a local isolate previously recovered from a soil sample in our lab and showed a promising cytotoxic activities against various cancer cell lines[11]. The production was carried out in $14 \mathrm{~L}$ laboratory fermentor under a previously determined optimum conditions [11] in order to recover sufficient pure quantities of the active metabolites as an attempt for structural elucidation. Bioassay guided fractionation using different chromatographic techniques had led to the purification of cytotoxic metabolites coded W1, R1 and R2 in amounts enough to identify the chemical structures of the respective metabolites using various techniques such as mass, 1D and 2D NMR spectroscopic analysis. According, to the obtained results, the structures of respective metabolites were determined and identified as genistein, $\beta$-rhodomycinone and $\gamma$ - rhodomycinone, respectively.

For the metabolite W1, the 1HMNR, ESI-MS and APT spectra were identical to those of the isoflavonoid aglycone genistein in the literature [18], thus metabolite W1 was unambiguously identified as genistein. However, till now it was not reported in literature that genistein is produced by Streptomyces sp. including S. griseus. Accordingly, this is the first report of the production of genistein by our studied isolate S. griseus KJ623766. Genistein is an isoflavone metabolite found in a number of plants such as lupin, soybeans, kudzu, fava beans and psoralea being the principal food source[19,20] as well as in some medicinal plants, including Flemingia vestita[21] and $F$. macrophylla[22,23], coffee[24] and in Maackia amurensis cell culture[25]. Genistein showed potent cytotoxic activity against $\mathrm{Caco} 2$ cell line, where $\mathrm{CD}_{50}$ against Caco2, Hela and Vero cell lines are $4.05 \mu \mathrm{g} / \mathrm{ml}, 5.4 \mu \mathrm{g} / \mathrm{ml}$ and $43 \mu \mathrm{g} / \mathrm{ml}$ respectively. These results matched with that reported by Ganai and H. Farooqi [18] and Russo et al. [26] which showed the anticancer activity of genistein against human colon cancer.

The cytotoxic activity of genistein was previously determined by inhibiting the intracellular signal transduction pathway that support and potentiate cell proliferation and growth as well as promoting the angiogenesis process[27]. The activity of genistein against Hela cell line may be due to inhibition of the expression of VEGF and VEGF receptors and Down-regulation of the expression of miR-27a which lead to induction of cell cycle arrest [26].

Genistein was previously recognized to have some cellular actions including, glucose, lipid metabolism and other activities such as lipid peroxidation, inflammation, and fibrosis [28-30] as well as its antiviral activity against Herpes B Virus [31] and chondroprotective Effects against osteoarthritis [32].

For the metabolite R1, the ${ }^{1} \mathrm{H}$ NMR analysis showed a typical pattern of anthracycline derivatives and the spectrum revealed the presence of three adjacent aromatic protons corresponding to $\mathrm{H}-1, \mathrm{H}-2$ and $\mathrm{H}-3$, respectively. The presence of the two deshielded methine protons at $\delta \mathrm{H} 5.25(\mathrm{~m}, 1 \mathrm{H})$ and $\delta \mathrm{H} 4.91$ suggested the presence of two tertiary alcohol methine protons at $\mathrm{H}-7$ and $\mathrm{H}-10$, respectively. In addition, we confirmed its structure by using the COSY correlations where $\mathrm{H}-7$ showed strong correlations with the methylene protons $\mathrm{H}-8 \mathrm{a}$ and $\mathrm{H}-8 \mathrm{~b}$ at $\delta \mathrm{H} 2.19(\mathrm{~m}$, $1 \mathrm{H})$ and $\delta \mathrm{H} 2.22(\mathrm{~m}, 1 \mathrm{H})$ and when we compared the data of ${ }^{1} \mathrm{H}$ NMR spectrum of R1 ) with that of known anthracyclins in the literature, we found a strong similarity to the known metabolite $\beta$-rhodomycinone [33,34].

For the metabolite R2 $(1.5 \mathrm{mg})$, the ${ }^{1} \mathrm{HNMR}$ spectrum showed a strong similarity to metabolite R1 except in the replacement of $\mathrm{H}-7$ at $\delta \mathrm{H} 5.25(\mathrm{~m}, 1 \mathrm{H})$ in R1 with the methylene protons $\delta \mathrm{H} 2.98(\mathrm{~m}, 1 \mathrm{H})$ and $2.90(\mathrm{~m}, 1 \mathrm{H})$ corresponding to $\mathrm{H}-7 \mathrm{a}$ and $\mathrm{H}-7 \mathrm{~b}$ in R2. Comparison of ${ }^{1} \mathrm{HNMR}$ spectrum of R2 with that of known anthracyclins in 
the literature showed a strong similarity to the known metabolite $\gamma^{-}$rhodomycinone. This also was confirmed by EZI-MS which revealed pseudomolecular ion peak at m/z $369.09(\mathrm{M}-\mathrm{H})^{-}$that was matched to the molecular formula $\mathrm{C}_{20} \mathrm{H}_{18} \mathrm{O}_{7}[33,34]$.

Both $\beta$ - rhodomycinone (R1) and $\gamma$-rhodomycinone (R2) showed potent cytotoxic activity against Caco2 and Hela cell lines, the $\mathrm{CD}_{50}$ were $7.11 \mu \mathrm{g} / \mathrm{ml}$ and $9.35 \mu \mathrm{g} / \mathrm{ml}$ respectively. While lower cytotoxic activity was shown against Vero cell line $\left(\mathrm{CD}_{50}=67.3 \mu \mathrm{g} / \mathrm{ml}\right)$ confirming its applicability to be used as a potential anticancer drug in human.

These results matched with that of Tsuji et al. [35] which showed that $\mathrm{y}$-rhodomycinone, had no differentiation inducing activity, but was cytotoxic however, this cytotoxicity activity against normal cell lines was much lower than cancer cell lines. Supong and his co works recently showed that $\varepsilon$-rhodomycinone produced by a rare actinomycete Nonomuraea rhodomycinica NR4-ASC07 has a potential antimalarial activity[36]. Further studies should be conducted to explore the biosynthetic pathways of the respective metabolites as well as to produce new derivatives of the anthracycline family with higher antitumor activities and lower side effects. The later can be achieved by structural modifications or microbial transformation of the recovered metabolites.

\section{Conclusions}

This study targeting large scale production of cytotoxic metabolites by S. griseus isolate KJ623766 on 14L fermentor and studying different recovery methods for downstream processing. The structures of isolated metabolites were determined based on the mass, 1D and 2D NMR spectroscopic analysis and identified as genistein, $\beta$-rhodomycinone and $\gamma$ - rhodomycinone, respectively. The respective metabolites were biologically analyzed using various cancer cell lines for their cytotoxic actives and exhibiting promising cytotoxic activities. Accordingly, S. griseus isolate KJ623766 can be used as an industrial strain for the commercial production of the isoflavonoid genistein, as well as the production of $\beta$-rhodomycinone and $\gamma$-rhodomycinone to be used for production of different derivatives of antitumor antibiotics of the anthracycline family.

\section{Declarations}

\section{Ethics approval and consent to participate}

not applicable

\section{Consent to publish}

not applicable

\section{Availability of data and materials}

All data generated or analyzed during this study are included in this published article in the main manuscript and additional supporting file.

\section{Competing interests}

The authors declare that they have no competing interests

\section{Funding}


No funding source was received. The article is self funded by the authors. All authors shared in the design of the study, collection, analysis, and interpretation of data and in writing the manuscript.

\section{Authors' contributions}

All authors contributed extensively to the work presented in this paper. ASA and AEA designed, performed the experiments and wrote the first draft of the manuscript. KMA, and MAY designed the experiments, analyzed data and revised the manuscript. NH supervised and approved the manuscript. All authors discussed the results and commented on the manuscript at all stages.

\section{Acknowledgement}

Authors would like acknowledge "Center for Drug Discovery and Development Research, Department of Microbiology and Immunology, Faculty of Pharmacy, Ain-Shams University” for their support and providing facilities whenever needed

\section{Authors' Information}

ASA is assistant lecturer in the Department of Microbiology and Immunology, Faculty of Pharmacy, Ain Shams University, Cairo, Egypt. AEA, is a lecturer in the Department of Pharmacognosy, Faculty of Pharmacy, Ain Shams University, Cairo, Egypt. KMA, a professor and vice Dean for postgraduate affairs and Scientific Research, Faculty of Pharmacy, Ain Shams University, Cairo, Egypt. MAY, a professor and vice Dean for student affairs, Faculty of Pharmacy, Ain Shams University, Cairo, Egypt and NAH is a professor of Microbiology and Immunology,. Faculty of Pharmacy, Ain Shams University, Cairo, Egypt

\section{References}

[1] Hernandez BY, Green MD, Cassel KD, Pobustsky AM, Vu V, Wilkens LR. Preview of Hawaii cancer facts and figures 2010. Hawaii Med J. 2010; 69 (6): 223-224. PMID: 20848386

[2] Poustchi H, Sepanlou S, Esmaili S, Mehrabi N, Ansarymoghadam A. Hepatocellular Carcinoma in the World and the Middle East. Middle East J Dig Dis.2010; 2(1): 32-37. PMID:25197510

[3] Jennifer R, Robin V, Rebecca M. Effectively Communicating Colorectal Cancer Screening Information to Primary Care Providers. Am J Health Educ.2012; 43(4): 194-201.

https://doi.org/10.1080/19325037.2012.10599235

[4] Najjar H, Easson A. Age at diagnosis of breast cancer in Arab nations. Int J Surg.2010; 8(6): 448-52. https://doi.org/10.1016/j.ijsu.2010.05.012

[5] Youssef MA, Abdelsalam L, Harfoush RA, Talaat IM, Elkattan E, Mohey A. Prevalence of human papilloma virus (HPV) and its genotypes in cervical specimens of Egyptian women by linear array HPV genotyping test. Infect Agent Cancer. 2016; 11 (6). https://doi.org/10.1186/s13027-016-0053-1

[6] Abdel-Hadi M, Khalaf A, Aboulkassem H, Naeem N, AbdelBaqy M, Sallam H. Cervical intraepithelial lesions in females attending Women's Health Clinics in Alexandria, Egypt. Cytojournal.2015; 12(13). https://doi.org/10.4103/1742-6413.159240 
[7] Mann J. Natural products in cancer chemotherapy: past, present and future. Nat Rev Cancer.2002; 2(2):143148. https://doi.org/10.1038/nrc723

[8] Pettit GR, Pierson FH, Herald CL. Anticancer Drugs from Animals, Plants, and Microorganisms. J Chem Technol Biotechnol.1996;66(1): 106 https://doi.org/10.1002/(SICI)1097-4660(199605)66:1<3C106:AIDJCTB2466>3E3.0.C0;2-3

[9] Tan LTH, Ser HL, Yin WF, Chan KG, Lee LH, Goh BH. Investigation of Antioxidative and Anticancer Potentials of Streptomyces sp. MUM256 Isolated from Malaysia Mangrove Soil. Front Microbiol.2015;6. https://doi.org/10.3389/fmicb.2015.01316

[10] Gui C, Yuan J, Mo X, Huang H, Zhang S, Gu YC, Ju J. Cytotoxic Anthracycline Metabolites from a Recombinant Streptomyces. Nat Prod.2018; 81(5):1278-1289. doi: 10.1021/acs.jnatprod.8b00212

[11] Abu Zaid AS, Aboshanab KM, Yassien MA, Hassouna NA. Improvement the production of cytotoxic metabolites by Streptomyces griseus KJ623766. Arch Pharm Sci Ain Shams University.2017; 1(2):31-38. DOI: 10.21608/aps.2017.11022

[12] Osada N, Kohara A, Yamaji T, Hirayama N , Kasai F, Sekizuka T, Kuroda M, Hanada K. The genome landscape of the african green monkey kidney-derived vero cell line. DNA Res.2017;21(6):673-83. doi: $10.1093 /$ dnares/dsu029

[13] Yin P, Wang YH, Zhang SL, Chu J, Zhuang YP, Wang ML, Zhou J. Isolation of soluble proteins from an industrial strain Streptomyces avermitilis in complex culture medium for two-dimensional gel electrophoresis. J Microbiol Methods.2008; 73(2):105-10. doi: 10.1016/j.mimet.2008.02.012.

[14] Radwan HH, Moussa IM, Alsarra IA. Optimization of a fed-batch fermentation process for production of bleomycin by Streptomyces mobaraensis ATCC 15003. Afr J Biotechnol.2013;10(9) 9: 1690-1965.

[15] Maskey RP, Helmke E, Kayser O, Fiebig HH, Maier A, Busche A, Laatsch H. Anti-cancer and antibacterial trioxacarcins with high anti-malaria activity from a marine Streptomycete and their absolute stereochemistry. J Antibiot (Tokyo).2004; 57(12):771-779. PMID:15745111

[16] Atta HM, El-Sehrawi MH, Bahobail AS. Antifungal Macrodiode Production By Streptomyces albidoflavus-143: Fermentation, Purification and Biological Activities. J Am Sci.2011; 7(3): 13-22, 2011.

[17] Saliba AM, Filloux A, Ball G, Silva ASV, Assis MC, Plotkowski MC. Type III secretion-mediated killing of endothelial cells by Pseudomonas aeruginosa. Microb Pathog.2002; 33(4): 153-166. PMID:12385743

[18] Ganai AA, Farooqi H. Bioactivity of genistein: A review of in vitro and in vivo studies," Biomed Pharmacother Biomedecine Pharmacother.2015; 76: 30-38.

[19] Coward L, Barnes NC, Setchell KDR, Barnes, Stephen B. Genistein, daidzein, and their $\beta$-glycoside conjugates: Antitumor isoflavones in soybean foods from American and Asian diet. J Agric Food Chem.1993; 41(11):19611967. doi:10.1021/jf00035a027.

[20] Kaufman PB, Duke JA, Brielmann H, Boik J, Hoyt JE. A Comparative Survey of Leguminous Plants as Sources of the Isoflavones, Genistein and Daidzein: Implications for Human Nutrition and Health. J Altern 
Complement Med.1997; 3(1):7-12. doi:10.1089/acm.1997.3.7.

[21] Rao HSP, Reddy, KS. Isoflavones from Flemingia vestita. Fitoterapia.1991;62 (5): 458.

[21] Rao KN, Srimannarayana G. Fleminone, a flavanone from the stems of Flemingia macrophylla. Phytochemistry.1983; 22 (10): 2287-90. doi:10.1016/S0031-9422(00)80163-6.

[23] Wang B-S, Juang L-J, Yang J-J, Chen L-Y, Tai Huo-M, Huang M-H. Antioxidant and Antityrosinase Activity of Flemingia macrophylla and Glycine tomentella Roots. Evid Based Complement Alternat Med,2012; 2012: 1-7. doi:10.1155/2012/431081.

[24] Ives R, Almeida IMC, Casal S, Oliveira MB, Beatriz PP. Isoflavones in Coffee: Influence of Species, Roast Degree, and Brewing Method. J Agric Food Chem, 2010; 58 (5): 3002-3007. doi:10.1021/jf9039205.

[25] Fedoreyev SA, Pokushalova TV, Veselova MV, Glebko LI, Kulesh NI, Muzarok TI, Seletskaya LD, Bulgakov VP, Zhuravlev YuN. Isoflavonoid production by callus cultures of Maackia amurensis. Fitoterapia.2000;71 (4): $365-72$. doi:10.1016/S0367-326X(00)00129-5.

[26] Russo M, Russo GL, Daglia M , Kasi PD, Ravi S, Nabavi SF, Nabavi SM. Understanding genistein in cancer: The "good" and the "bad" effects: A review. Food Chem.2015;196:589-600. doi: 10.1016/j.foodchem.2015.09.085

[27] Pintova S, Dharmupari S, Moshier E, Zubizarreta N, Ang C, Holcombe RF. Genistein combined with FOLFOX or FOLFOX-Bevacizumab for the treatment of metastatic colorectal cancer: phase I/II pilot study. Cancer Chemother Pharmacol.2019; doi: 10.1007/s00280-019-03886-3

[28] Xin X, Chen C, Hu YY, Feng Q. Protective effect of genistein on nonalcoholic fatty liver disease (NAFLD) Biomed Pharmacothern.2019;117:109047. doi: 10.1016/j.biopha.2019.109047

[29] Zhao D, Yin J, Wu S, Wu Z, Pan H. Effects of genistein on proliferation and invasion of human thyroid squamous cell carcinoma SW579 cells. Wei Sheng Yan Jiu.2018;47(6):984-992. PMID:30593333

[30] Fan J, Cheng L, Hu P, Liu R. The anticancer activity of genistein is increased in estrogen receptor beta 1positive breast cancer cells. Onco Targets Ther.2018;11:8153-8163. doi: 10.2147/OTT.S182239.

[31] LeCher JC, Diep N, Krug PW, Hilliard JK. Genistein Has Antiviral Activity against Herpes B Virus and Acts Synergistically with Antiviral Treatments to Reduce Effective Dose. Viruses.2019; 11(6):499. doi: 10.3390/v11060499

[32] Liu FC1, Wang CC2, Lu JW3, Lee CH4, Chen SC5, Ho YJ6, Peng YJ. Chondroprotective Effects of Genistein against Osteoarthritis Induced Joint Inflammation. Nutrients.2019;11(5):1180. doi: 10.3390/nu11051180.

[33] Cho I, Chung J, Rho Y, Rhee R. Synthesis of $\pm Y$-Rhodomycinone and 10 deoxy $Y$-Rhodomycinone, aglycone of antitumor antibiotic rhodomycin. J Korean Chem Soc.1988;32(6): 575-580.

[34] Holkar S, Begde D,Nashikkar N, Kadam T, Upadhyay A. Rhodomycin analogues from Streptomyces purpurascens: isolation, characterization and biological activities," SpringerPlus.2013;2(1):93.doi: 10.1186/21931801-2-93. 
[35] Tsuji T, Morioka H, Takezawa M, Ando T, Murai A, Shibai H. Differentiation Inducing Activity of Anthracycline Compounds in Friend Leukemia Cells. Agric Biol Chem.1986;50(7):1697-1701.

https://doi.org/10.1271/bbb1961.50.1697.

[36] Supong K, Sripreechasak P, Phongsopitanun W, Tanasupawat S, Danwisetkanjana K, Bunbamrung N, Pittayakhajonwut P. Antimicrobial substances from the rare actinomycete Nonomuraea rhodomycinica NR4ASC07T. Nat Prod Res.2019;33(16):2285-2291. doi: 10.1080/14786419.2018.1440223.

\section{Figures}

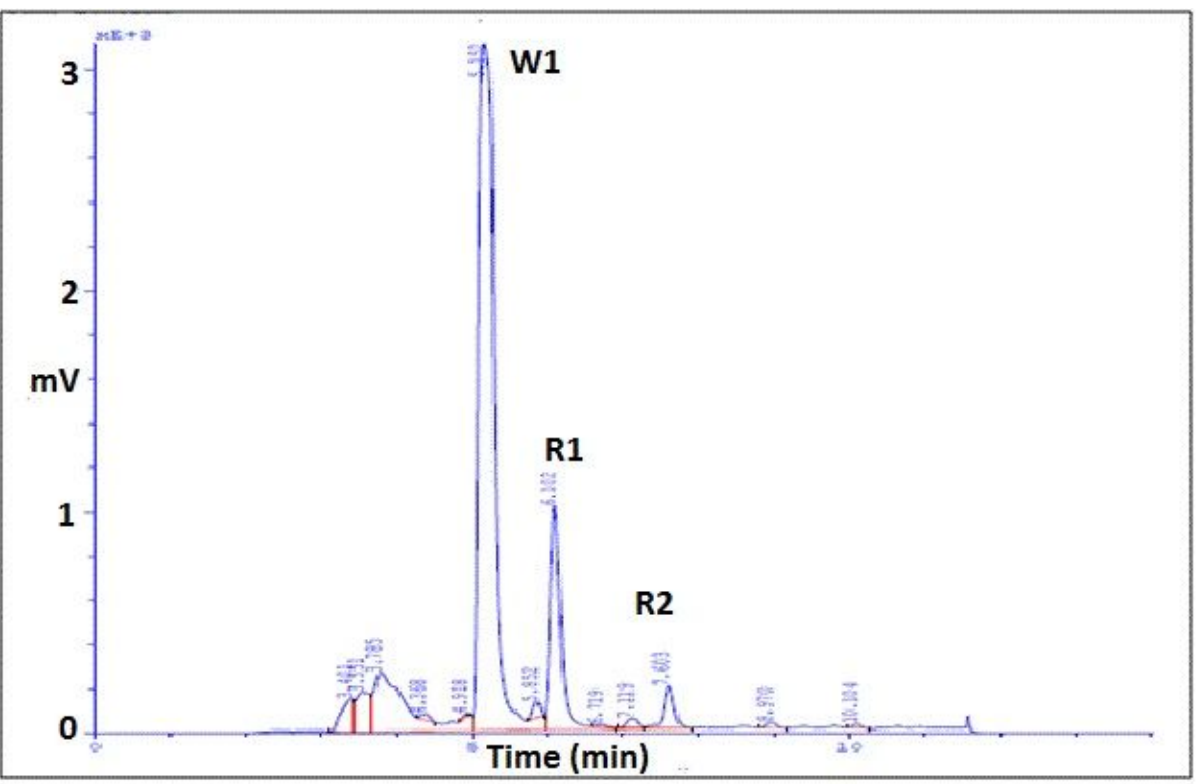

Figure 1 
HPLC analysis of fraction SG-3

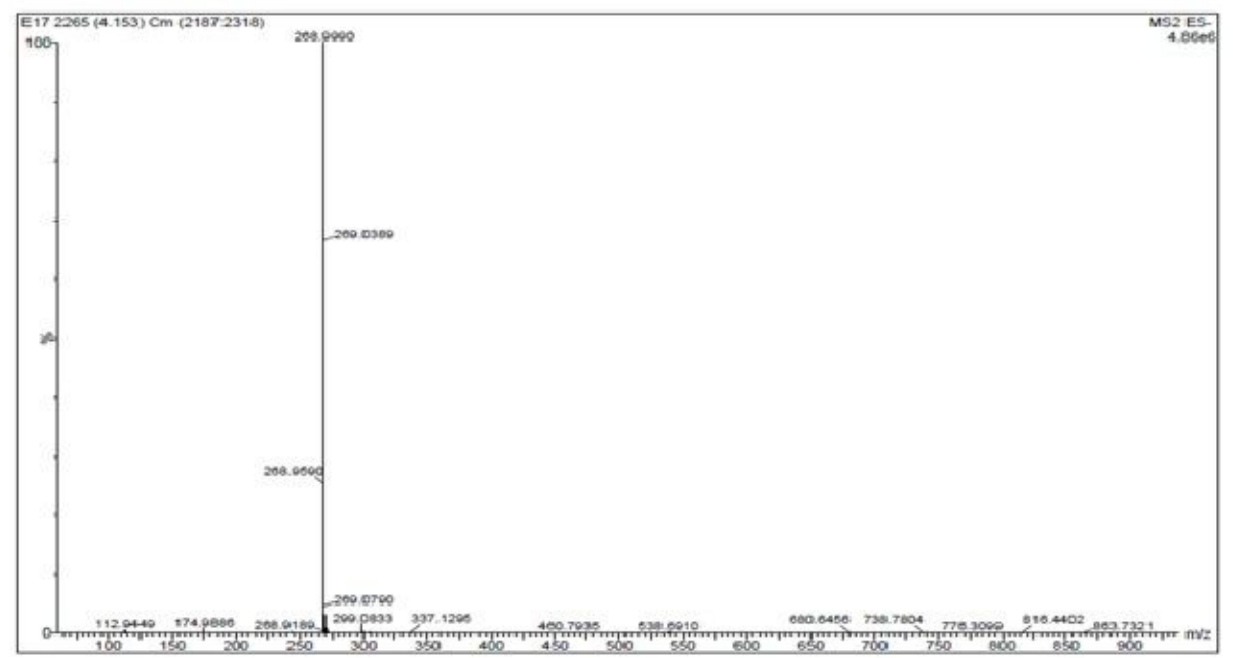

Figure 2

ESI-MS of isolated compound W1 


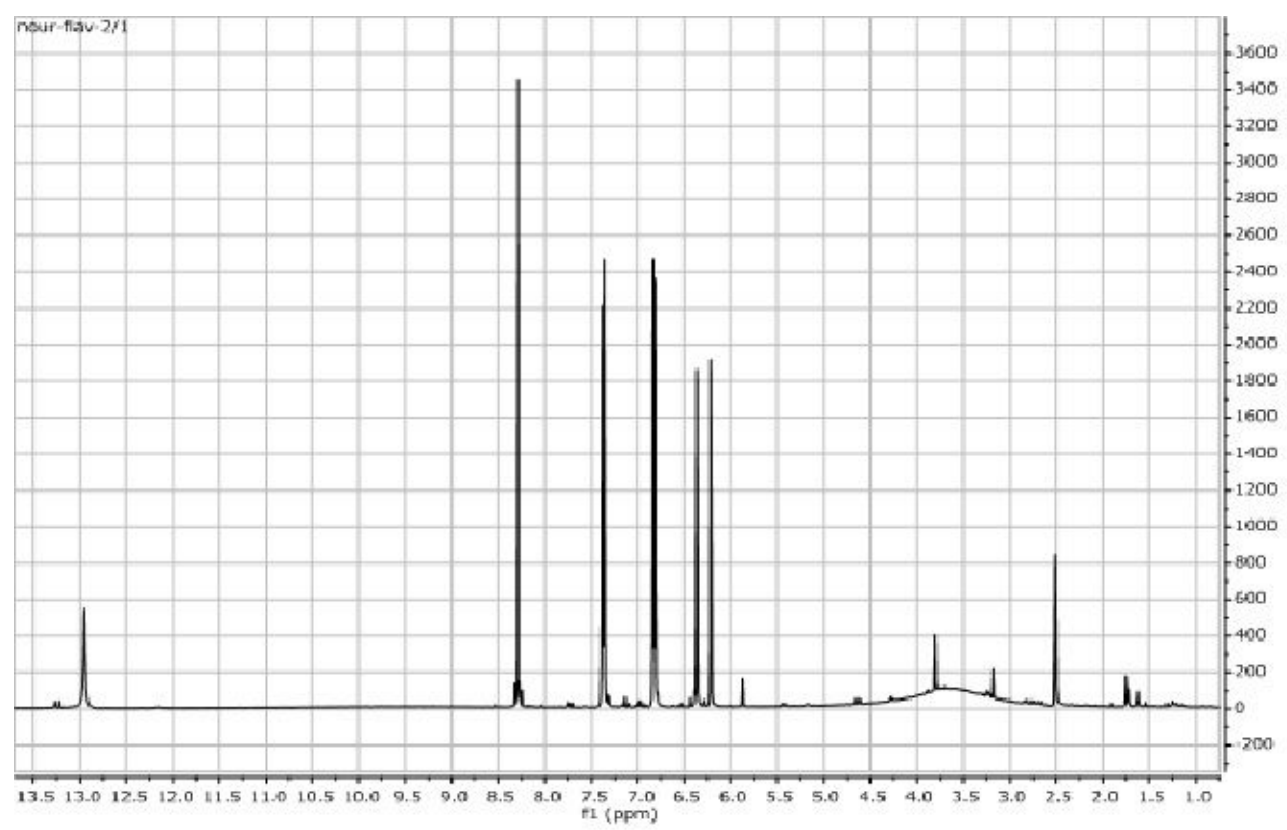

Figure 3

1HMNR spectra of isolated compound W1 


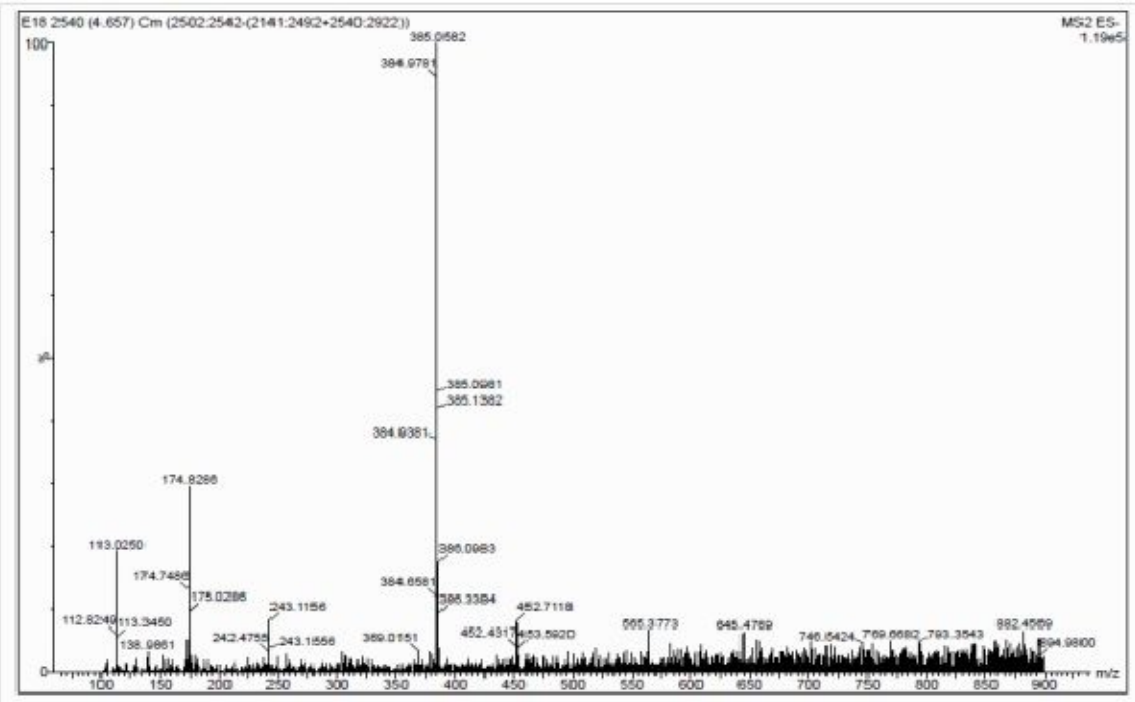

Figure 4

ESI-MS of isolated compound R1.

Page 16/19 


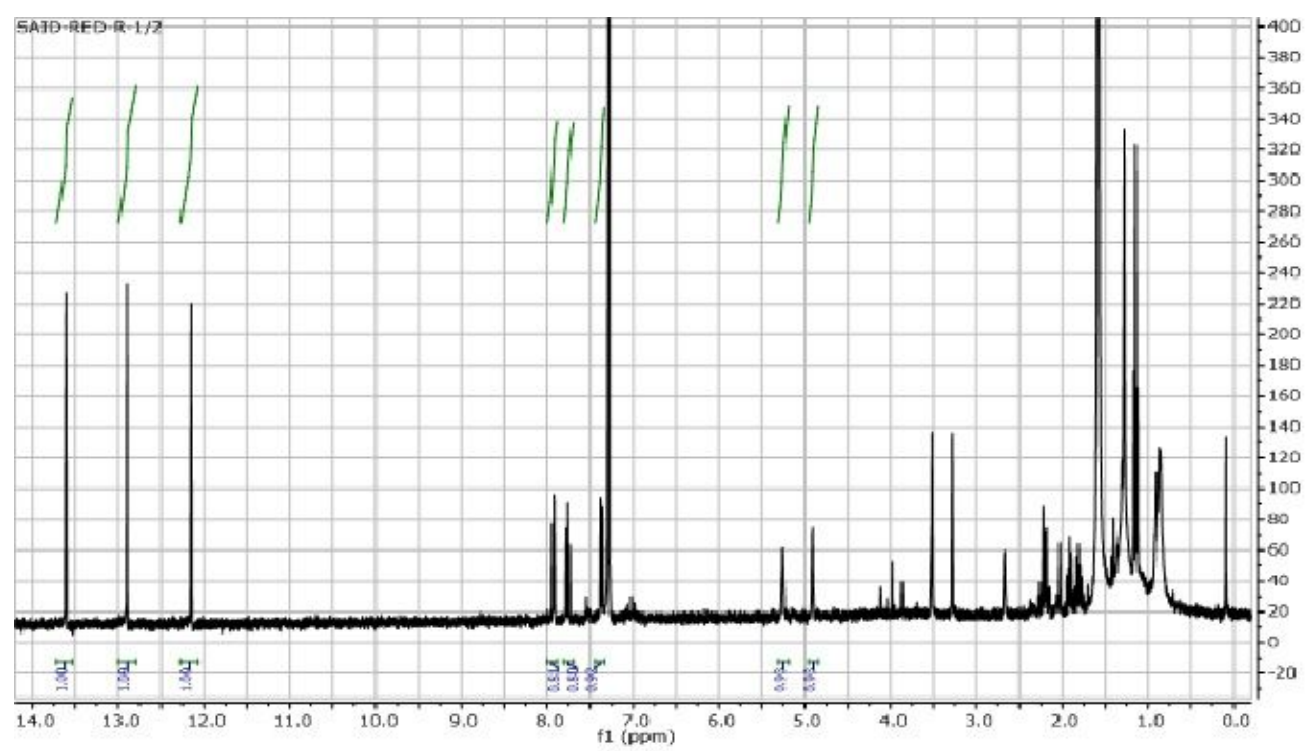

Figure 5

1HMNR spectra of isolated compound R1. 


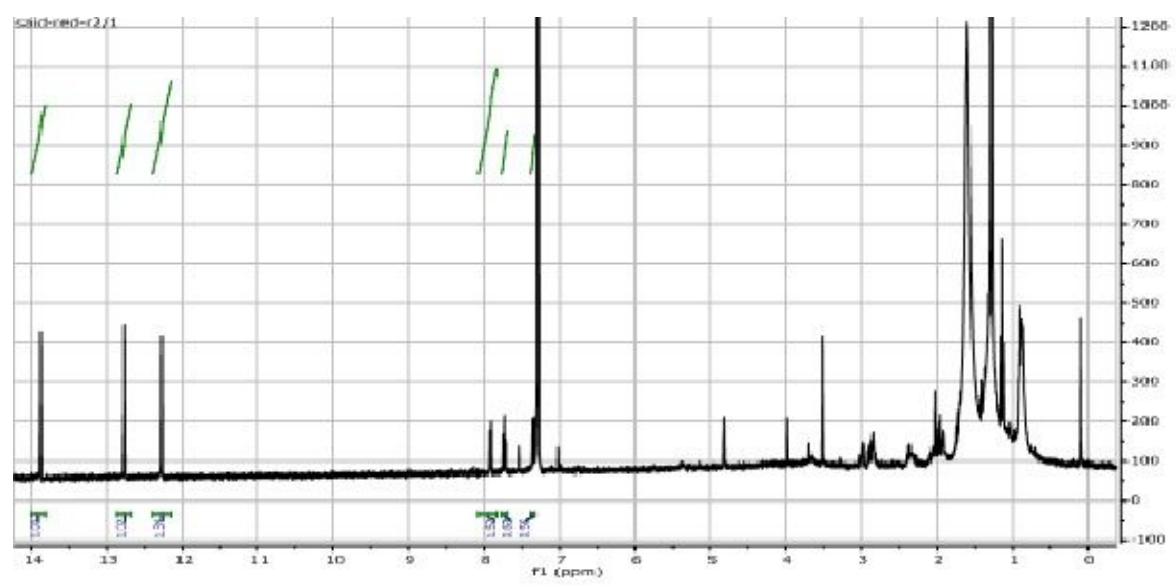

Figure 6

1HMNR spectra of isolated compound R2. 


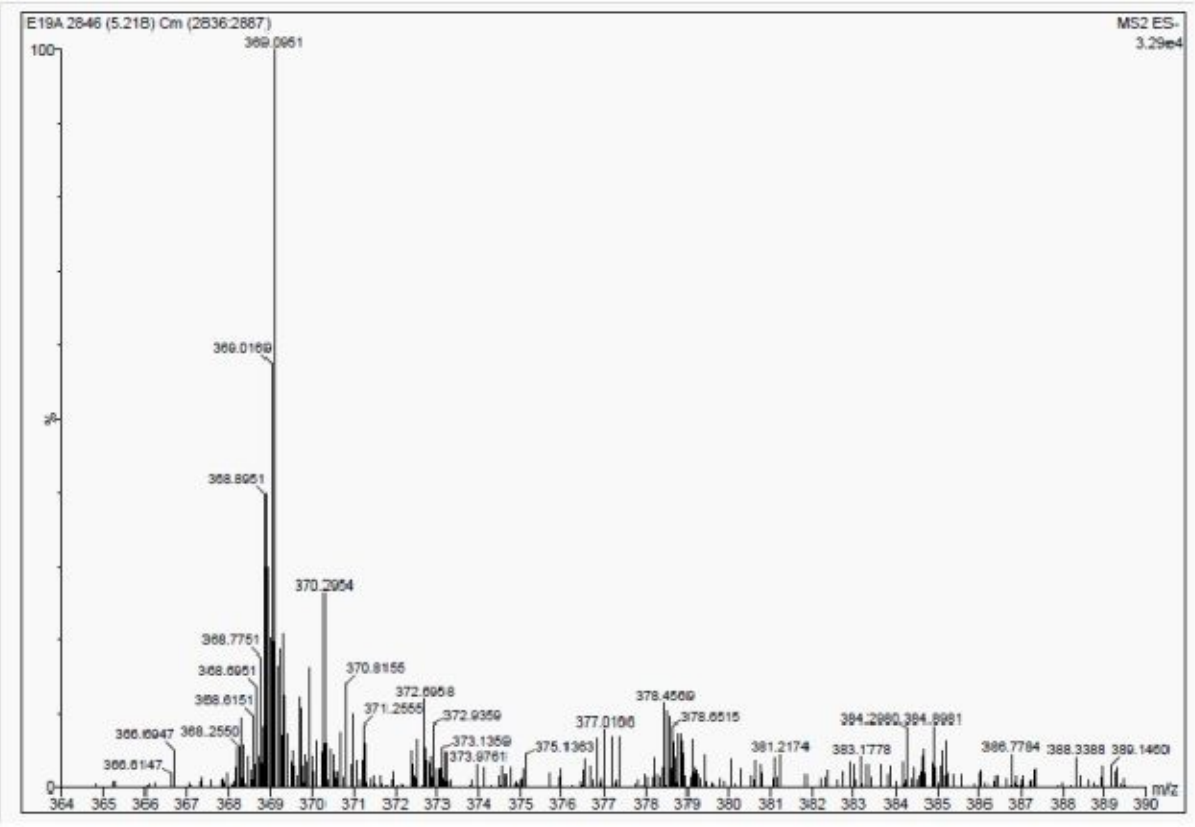

Figure 7

ESI-MS of isolated compound R2.

\section{Supplementary Files}

This is a list of supplementary files associated with this preprint. Click to download.

- Fig.2S.jpg

- Fig.1S.jpg

- Fig.3S.jpg 